\title{
Tingkat kepuasan pasien dewasa pada pelayanan Radiografi panoramik di instalasi radiologi Rumah Sakit Gigi dan Mulut Maranatha
}

\author{
Wine Meilasari ${ }^{1 *}$, Winny Suwindere ${ }^{1}$, Hendra Polii $^{2}$ \\ ${ }^{1}$ Departemen Ilmu Kesehatan Gigi Masyarakat, Fakultas Kedokteran Gigi, Universitas Kristen \\ Maranatha, Indonesia \\ ${ }^{2}$ Departemen Radiologi Kedokteran Gigi, Fakultas Kedokteran Gigi, Universitas Kristen Maranatha, \\ Indonesia
}

*Korespondensi: meilasari.wine@gmail.com

\begin{abstract}
ABSTRAK
Pendahuluan: Kepuasan pasien merupakan salah satu indikator keberhasilan pelayanan kesehatan yang semakin banyak dipakai sebagai alat ukur yang dipercaya untuk menilai keberhasilan penyelenggaraan pelayanan kesehatan yang baik dan pada akhirnya dapat meningkatkan kesehatan masyarakat. Salah satu sarana pelayanan kesehatan yang tersedia dalam bidang kesehatan gigi dan mulut adalah Rumah Sakit Gigi dan Mulut. RSGM adalah sarana pelayanan kesehatan yang menyelenggarakan pelayanan rawat jalan, gawat darurat, pelayanan medik dan pelayanan penunjang, salah satunya adalah pelayanan radiologi kedokteran gigi. Tujuan dari penelitian ini yaitu untuk dapat memberikan data yang akurat tentang kepuasan pasien radiografi panoramik di instalasi radiologi Rumah Sakit Gigi dan Mulut Maranatha dan memberikan hasil penelitian pada pihak rumah sakit agar dapat meningkatkan kualitas pelayanan yang optimal dan meningkatkan jumlah kunjungan pasien. Metode: Jenis penelitian ini adalah deskriptif analitik dengan teknik survei. Semua data diperoleh menggunakan uji statistik oneway anova yang diolah menggunakan program komputer SPSS. Hasil: Sebagian besar responden menyatakan puas pada dimensi Reliability (kehandalan) dengan skor 95,25 \%, Assurance (jaminan/keyakinan) dengan skor 94,6\%, Tangibles (penampilan) dengan skor $100 \%$, Empathy (perhatian) dengan skor 100\% Responsiveness (ketanggapan) yaitu memiliki skor 100\%. Simpulan: Pelayanan pemeriksaan radiografi panoramik di Rumah Sakit Gigi dan Mulut Maranatha pada periode 18 Juli - 18 Agustus 2017 sangat baik, dengan tingkat kepuasan yang tinggi pada dimensi kualitas pelayanan reliability (kehandalan), assurance (jaminan/keyakinan), tangibles (penampilan), empathy (perhatian) dan responsiveness (ketanggapan).
\end{abstract}

Keywords: Pelayanan, kepuasan, radiografi panoramik

\section{Description of adult patient satisfaction on panoramic Radiography services in radiological installation of dental Hospital Maranatha}

\begin{abstract}
Introduction: Patient satisfaction is one indicator of the success of health services are widely used as a measuring tool that is believed to assess the successful implementation of good health services and ultimately can improve public health. One of the health service facilities available in the field of oral health is RSGM. RSGM is a health service facility that provides outpatient services, emergency room, medical service and support services, one of them is radiology service of dentistry. The purpose of this research is to be able to provide accurate data about patient satisfaction of panoramic radiography at radiology instalation of RSGM Maranatha Bandung and to give result of research at hospital side in order to improve optimal service quality and increase the number of patient visits. Method: The research method used in this research is descriptive analytic with survey technique. All data were obtained using oneway anova statistical test which was processed using SPSS computer program. Result: Most of respondents stated that they are satisfied on Reliability dimension with 95,25\% score, Assurance dimension with score 94,6\%, Tangibles dimension with 100\% score, Empathy dimension with 100\% score, Responsiveness dimension with 100\% score. Conclusion: the service of panoramic radiography examination at RSGM Maranatha in the period of 18 July - 18 August 2017 is very good, with high satisfaction level on service quality dimension reliability, assurance, tangibles, empathy and responsiveness.
\end{abstract}

Keywords: Service, Satisfaction, Panoramic Radiography. 


\section{PENDAHULUAN}

Seperti yang telah kita ketahui bahwa dalam rangka memasuki era pasar bebas, tuntutan mutu pelayanan kesehatan khususnya pelayanan kesehatan gigi dan mulut, terus menerus meningkat. ${ }^{1}$ Semakin majunya ilmu pengetahuan dan teknologi kedokteran gigi, maka akan semakin meningkat pula kebutuhan, harapan pasien dan tuntutan sarana pelayanan kesehatan yang berkualitas dari masyarakat. Salah satu sarana pelayanan kesehatan yang tersedia dalam bidang kesehatan gigi dan mulut adalah Rumah Sakit Gigi dan Mulut. Rumah Sakit Gigi Dan Mulut adalah sarana pelayanan kesehatan yang menyelenggarakan pelayanan kesehatan gigi dan mulut perorangan untuk pengobatan dan pemulihan tanpa mengabaikan pelayanan peningkatan kesehatan dan pencegahan penyakit yang dilaksanakan melalui pelayanan rawat jalan, gawat darurat, pelayanan medik dan pelayanan penunjang salah satunya adalah pelayanan radiologi kedokteran gigi. $^{2}$

Dalam meningkatkan suatu mutu pelayanan dari rumah sakit gigi dan mulut tersebut yaitu dengan mengetahui kepuasan pasien yang sesuai dengan standar pelayanan dan kode etik profesi yang telah ditetapkan serta diharapkan dapat memberikan pelayanan yang memuaskan bagi pasien. ${ }^{3}$ Tingkat kepuasan pasien dipengaruhi berbagai faktor lainnya seperti sikap pemberi pelayanan, kondisi ruangan, kelengkapan sarana dan fasilitas, termasuk di dalamnya hak pasien dari hak atas badan sendiri atau hak privasi.

Faktor lain yang mempengaruhi tingkat kepuasan pasien adalah kebutuhan dan keinginan, pengalaman masa lalu, pengalaman dari temanteman dan komunikasi melalui iklan pemasaran. Selain itu faktor umur, pendidikan, jenis kelamin, kepribadian, suku dan latar belakang budaya, serta kasus penyakit turut mempengaruhi persepsi dan ekspektasi pasien. ${ }^{5}$ Menurut penelitian yang telah dilakukan faktor yang mempengaruhi kepuasan pasien menunjukan hasil yang signifikan pada kualitas pelayanan rumah sakit serta tingkat perasaan seseorang setelah membandingkan kinerja atau hasil yang dirasakan dibandingkan dengan harapannya. ${ }^{4}$ Penelitian mengenai tingkat kepuasan pasien dewasa pada pelayanan radiografi panoramik di instalasi radilogi Rumah Sakit Gigi dan Mulut Maranatha akan berdampak positif bagi pihak rumah sakit agar kualitas pelayanan yang diberikan dapat mengutamakan kepuasan pasien, berdasarkan latar belakang penulis tertarik dengan penelitian ini karena radiologi kedokteran gigi memegang peranan penting dalam diagnosa dan perawatan bagi dokter gigi yang bertujuan untuk memberikan data yang akurat tentang kepuasan pasien di instalasi radiologi Rumah Sakit Gigi dan Mulut Marantha dan memberikan hasil penelitian pada pihak rumah sakit agar dapat meningkatkan kunjungan pasien serta meningkatkan pelayanan yang optimal terutama pada instalasi radiologi. Tujuan dari penelitian ini yaitu untuk dapat memberikan data yang akurat tentang kepuasan pasien radiografi panoramik di instalasi radiologi Rumah Sakit Gigi dan Mulut Maranatha dan memberikan hasil penelitian pada pihak rumah sakit agar dapat meningkatkan kualitas pelayanan yang optimal dan meningkatkan jumlah kunjungan pasien.

\section{METODE}

Jenis penelitian ini adalah penelitian deskriptif analitik dengan menggunakan metode survei. Studi penelitian ini menggunakan rancangan cross sectional. Penelitian dilakukan di Instalasi Radiologi Rumah Sakit Gigi dan Mulut Maranatha yang akan dilaksanakan pada bulan Juli - Agustus 2017. Pengambilan sampel pasien dengan cara accidental sampling dimana sampel yang digunakan adalah seluruh pasien dewasa yang datang ke instalasi radiologi untuk melakukan foto radiografi panoramik dalam jangka waktu satu bulan.

Variabel dalam penelitian ini yaitu tingkat kepuasan pasien dewasa pada pelayanan radiografi panoramik di instalasi radiologi Rumah Sakit Gigi Dan Mulut Maranatha Bandung. Tingkat Kepuasan Pasien: Respons evaluatif, afektif atau emosional yang terkait dengan mutu pelayanan yang diberikan rumah sakit serta harapan pasien terhadap pelayanan tersebut.13 Diukur dengan menggunakan kuesioner. Sub variabel dalam penelitian yaitu Reliability: Kemampuan untuk memberikan pelayanan yang sesuai dengan janji yang ditawarkan; Assurance: Kemampuan karyawan atas pengetahuan terhadap produk secara tepat, jaminan keselamatan, keterampilan dalam memberikan keamanan di dalam memanfaatkan jasa yang ditawarkan, dan kemampuan dalam menanamkan kepercayaan pelanggan terhadap perusahaan; Tangibles: Wujud kenyataan secara fisik yang meliputi penampilan dan kelengkapan fasilitas fisik; Emphaty: Perhatian 
secara individual yang diberikan rumah sakit terhadap pasien dan keluarganya; Responsiveness: Respons atau kesigapan karyawan dalam membantu pelanggan dan memberikan pelayanan yang cepat dan tanggap6 ; Radiografi panoramic secara umum di kedokteran gigi untuk mendapatkan gambaran utuh dari keseluruhan maksilofasial.7 Pada penelitian ini peneliti akan membatasi sampel yaitu pada pada pasien yang melakukan foto radiografi panoramik. .

\section{HASIL}

Penelitian ini dilakukan untuk mengetahui gambaran tingkat kepuasan pasien dewasa pada pelayanan radiografi panoramik di instalasi radiologi Rumah Sakit Gigi dan Mulut Maranatha Bandung dengan menggunakan kuesioner. Tingkat kepuasan ini diklasifikasikan menjadi tiga kategori, yaitu tinggi, sedang dan rendah. Kategori tinggi jika persentase skor melebihi 75\%, kategori sedang jika persentase skor berkisar dari 50\% - 75\% dan kategori rendah jika persentase skor kurang dari 50\%. Subjek penelitian pada pelayanan radiografi panoramik di instalasi radiologi Rumah Sakit Gigi dan Mulut Maranatha Bandung berjumlah 68 responden yang memenuhi kriteria dari populasi penelitian

Tabel 1. Karakteristik responden

\begin{tabular}{ccc}
\hline Karaktersitik Responden & Frekuensi & Persentase (\%) \\
\hline Usia & 6 & 8,8 \\
$<20$ Tahun & 37 & 54,4 \\
$21-30$ Tahun & 13 & 19,1 \\
$31-40$ Tahun & 7 & 10,3 \\
41 - 50 Tahun & 5 & 7,4 \\
$>50$ Tahun & & \\
Jenis Kelamin & 40 & 58,8 \\
Laki-laki & 28 & 41,2 \\
Perempuan & & \\
Frekuensi foto panoramik & 21 & 30,9 \\
Tidak Pernah & 37 & 54,4 \\
1 Kali & 10 & 14,7 \\
2 Kali & &
\end{tabular}

Tabel 2. Kepuasan responden berdasarkan dimensi reliability

\begin{tabular}{|c|c|c|c|}
\hline Dimensi reliability & Alternatif Jawaban & Frekuensi & $\%$ \\
\hline \multirow{5}{*}{$\begin{array}{l}\text { Proses pengambilan foto radiografi gigi berjalan } \\
\text { dengan baik dan lancar tanpa pengulangan } \\
\text { pengambilan foto radiografi gigi. }\end{array}$} & Sangat Setuju & 35 & 51,5 \\
\hline & Setuju & 30 & 44,1 \\
\hline & Kurang Setuju & 3 & 4,4 \\
\hline & Tidak Setuju & 0 & 0,0 \\
\hline & Total & 68 & 100,0 \\
\hline \multirow{5}{*}{$\begin{array}{l}\text { Lamanya waktu untuk dipanggil giliran untuk } \\
\text { dilakukan pemeriksaan radiografi gigi cepat }\end{array}$} & Sangat Setuju & 44 & 6,7 \\
\hline & Setuju & 21 & 30,9 \\
\hline & Kurang Setuju & 3 & 4,4 \\
\hline & Tidak Setuju & 0 & 0,0 \\
\hline & Total & 68 & 100,0 \\
\hline
\end{tabular}




\begin{tabular}{|c|c|c|c|}
\hline \multirow{5}{*}{$\begin{array}{l}\text { Petugas pelayanan pendaftaran radiologi ramah } \\
\text { pada pasien. Lamanya waktu untuk dipanggil } \\
\text { giliran untuk dilakukan pemeriksaan radiografi } \\
\text { gigi cepat }\end{array}$} & Sangat Setuju & 42 & 69,1 \\
\hline & Setuju & 21 & 30,9 \\
\hline & Kurang Setuju & 3 & 0,0 \\
\hline & Tidak Setuju & 0 & 0,0 \\
\hline & Total & 68 & 100,0 \\
\hline \multirow{5}{*}{$\begin{array}{l}\text { Kemampuan petugas cukup terampil dalam } \\
\text { menjalankan alat radiografi gigi }\end{array}$} & Sangat Setuju & 48 & 70,6 \\
\hline & Setuju & 19 & 27,9 \\
\hline & Kurang Setuju & 1 & 1,5 \\
\hline & Tidak Setuju & 0 & 0,0 \\
\hline & Total & 68 & 100,0 \\
\hline \multirow{5}{*}{$\begin{array}{l}\text { Mendapatkan penjelasan mengenai bahaya } \\
\text { radiasi yang mungkin ditimbulkan dan cara } \\
\text { perlindungannya dari petugas sebelum } \\
\text { pemeriksaan }\end{array}$} & Sangat Setuju & 22 & 32,4 \\
\hline & Setuju & 36 & 52,9 \\
\hline & Kurang Setuju & 8 & 11,8 \\
\hline & Tidak Setuju & 2 & 2,9 \\
\hline & Total & 68 & 100 \\
\hline \multirow{5}{*}{ Lokasi instalasi radiologi gigi mudah di temukan } & Sangat Setuju & 4 & $\%$ \\
\hline & Setuju & 19 & 27,9 \\
\hline & Kurang Setuju & 0 & 0,0 \\
\hline & Tidak Setuju & 0 & 0,0 \\
\hline & Total & 68 & 100,0 \\
\hline \multirow{5}{*}{ Lokasi instalasi radiologi gigi mudah di temukan } & Sangat Setuju & 49 & 72,1 \\
\hline & Setuju & 19 & 27,9 \\
\hline & Kurang Setuju & 0 & 0,0 \\
\hline & Tidak Setuju & 0 & 0,0 \\
\hline & Total & 68 & 100,0 \\
\hline \multirow{5}{*}{$\begin{array}{l}\text { Ruangan dan tata letak alat yang berada di } \\
\text { dalam instalasi radiologi gigi terata rapi }\end{array}$} & Sangat Setuju & 49 & 72,1 \\
\hline & Setuju & 19 & 27,9 \\
\hline & Kurang Setuju & 0 & 0,0 \\
\hline & Tidak Setuju & 0 & 0,0 \\
\hline & Total & 68 & 100,0 \\
\hline \multirow{5}{*}{$\begin{array}{l}\text { Dimensi ruang tunggu nyaman untuk pasien } \\
\text { Assurance }\end{array}$} & Sangat Setuju & Alternatif Jawaban & 72,1 \\
\hline & Setuju & Sangat Setuju & 27,9 \\
\hline & Kurang Setuju & Setuju & 0,0 \\
\hline & Tidak Setuju & Kurang Setuju & 0,0 \\
\hline & Total & Tidak Setuju & 100,0 \\
\hline
\end{tabular}


Tabel 3. Kepuasan responden berdasarkan dimensi responsiveness

\begin{tabular}{|c|c|c|c|}
\hline & Alternatif Jawaban & Frekuensi & $\%$ \\
\hline \multirow{5}{*}{$\begin{array}{l}\text { Instruksi dan penjelasan } \\
\text { langkah-langkah/prosedur } \\
\text { pemeriksaan radiografi gigi yang } \\
\text { di berikan petugas (posisi duduk, } \\
\text { pemakaian apron, dll) jelas. }\end{array}$} & Sangat Setuju & 41 & 60,3 \\
\hline & Setuju & 26 & 38,2 \\
\hline & Kurang Setuju & 1 & 1,5 \\
\hline & Tidak Setuju & 0 & 0,0 \\
\hline & Total & 68 & 100,0 \\
\hline \multirow{6}{*}{$\begin{array}{l}\text { Komunikasi petugas baik dan } \\
\text { akrab dengan pasien selama } \\
\text { pelaksanaan foto rongent }\end{array}$} & Alternatif Jawaban & Frekuensi & $\%$ \\
\hline & Sangat Setuju & 38 & 55,9 \\
\hline & Setuju & 30 & 44,1 \\
\hline & Kurang Setuju & 0 & 0,0 \\
\hline & Tidak Setuju & 0 & 0,0 \\
\hline & Total & 68 & 100,0 \\
\hline \multirow{6}{*}{$\begin{array}{l}\text { Kepuasan responden } \\
\text { Berdasarkan Dimensi } \\
\text { pengetahuan }\end{array}$} & Alternatif Jawaban & 47 & 69,1 \\
\hline & Sangat Setuju & 20 & 29,4 \\
\hline & Setuju & 1 & 1,5 \\
\hline & Kurang Setuju & 0 & 0,0 \\
\hline & Tidak Setuju & 68 & 100,0 \\
\hline & Total & & \\
\hline
\end{tabular}

Tabel 4. Tingkat kepuasan pasien dewasa pada pelayanan radiografi panoramik secara keseluruhan

\begin{tabular}{cccc}
\hline Interval & Kategori & Frekuensi & \% \\
\hline $0 \%-49 \%$ & Rendah & 0 & 00,0 \\
$50 \%-75 \%$ & Sedang & 8 & 11,8 \\
$76 \%-100 \%$ & Tinggi & 60 & 88,2 \\
\hline Total & & $\mathbf{6 8}$ & $\mathbf{1 0 0 , 0}$ \\
\hline
\end{tabular}

Tabel 5. Kepuasan berdasarkan usia dengan oneway anova

\begin{tabular}{|c|c|c|c|c|c|}
\hline Usia & $\mathbf{N}$ & Skor Kepuasaan & & & p-value* \\
\hline$<=20$ tahun & 6 & 43,0 & 5,1 & 1,583 & 0,190 \\
\hline 21-30 tahun & 37 & 47,1 & 4,6 & & \\
\hline 31-40 tahun & 13 & 47,8 & 3,7 & & \\
\hline $41-50$ & 7 & 46,7 & 5,4 & & \\
\hline$>50$ tahun & 5 & 49,2 & 3,1 & & \\
\hline Total & 68 & 47,0 & 4,6 & & \\
\hline
\end{tabular}

Tabel 6. Tingkat kepuasan berdasarkan jenis kelamin

\begin{tabular}{cccccc}
\hline & & \multicolumn{3}{c}{ Skor Kepuasan } \\
\cline { 3 - 5 } Jenis Kelamin & $\mathbf{N}$ & Mean & Std. Deviation & t Statistic & p-value* $^{*}$ \\
\cline { 3 - 5 } & & 47.6 & 3.9 & 1.349 & 0.182 \\
Laki-laki & 40 & 46.1 & 5.3 & \\
\hline Perempuan & 28 & $\mathbf{4 6 . 9}$ & $\mathbf{4 . 6}$ & \\
\hline Total & $\mathbf{6 8}$ & &
\end{tabular}




\section{PEMBAHASAN}

Kepuasan pasien merupakan hal yang sangat subjektif, sulit diukur, dapat berubah-ubah, serta banyak sekali faktor yang berpengaruh sebanyak dimensi di dalam kehidupan manusia. ${ }^{6}$ Tingkat kepuasan pasien merupakan cermin dari kualitas pelayanan di rumah sakit. Tingkat kepuasan pasien adalah perbandingan antara harapan dan kenyataan. Dikatakan puas jika harapan lebih dari kenyataan dan dikatakan tidak puas jika harapan kurang dari kenyataan. ${ }^{9}$ Pelayanan radiologi merupakan pelayanan kesehatan yang menggunakan sinar pengion ataupun bahan radioaktif sehingga penggunaan bahan tersebut mempunyai dua sisi yang saling berlawanan, yaitu dapat sangat berguna bagi penegakan diagnosa dan terapi penyakit dan di sisi lain akan sangat berbahaya bila penggunaannya tidak tepat dan tidak terkontrol. ${ }^{14}$

Pelayanan kesehatan adalah upaya yang diselenggarakan sendiri atau bersama-sama dalam organisasi untuk memelihara dan meningkatkan kesehatan, mencegah dan menyembuhkan penyakit, memulihkan kesehatan perseorangan, keluarga, kelompok dan masyarakat. ${ }^{15}$ Kualitas pelayanan yang baik akan memberikan suatu kepuasan bagi pasien.

Kualitas pelayanan kepada masyarakat sangat tergantung pada individu dan sistem yang dipakai. Tenaga kesehatan dan tenaga penunjang medis serta non medis yang bertugas harus memahami cara melayani pasiennya dengan baik agar dapat memberikan kepuasan yang optimal. ${ }^{10}$ Konsep yang masih popular dalam pengukuran kepuasan pasien adalah dengan menggunakan konsep dimensi kualitas pelayanan yang dikembangkan oleh Zeithaml dan Parasuraman pada tahun $1990 .{ }^{6}$ Lima dimensi kualitas pelayanan tersebut mencakup sebagai berikut: Reliability (reliabilitas), Assurance (jaminan), Tangibles (tampilan/bukti fisik), Emphaty (empati), Responsiveness (ketanggapan dan kepedulian). ${ }^{6}$ Penilaian pelayanan instalasi radiologi dapat dilihat dari tingkat kepuasan pasien terhadap pelayanan yang telah diberikan. Pelayanan yang baik juga merupakan suatu keharusan apabila manajemen rumah sakit ingin menarik jumlah pasien yang lebih banyak lagi

Berdasarkan hasil perhitungan pada tabel 7 menunjukan gambaran tingkat kepuasan pasien dewasa pada pelayanan radiografi panoramik di instalasi radiologi Rumah Sakit Gigi dan Mulut
Maranatha Bandung, yang berada pada kategori tinggi atau sangat puas yaitu sebesar $88,2 \%$ dan yang masuk dalam kategori sedang adalah sebesar $11,8 \%$ serta tidak ada yang masuk dalam kategori rendah. Berdasarkan hal tersebut dapat disimpulkan bahwa sebagian besar pasien dewasa merasa sangat puas terhadap pelayanan radiografi panoramik di instalasi radiologi Rumah Sakit Gigi dan Mulut Maranatha Bandung. Tabel 8 karakteristik responden menjelaskan bahwa skor kepuasan untuk berbagai rentang usia tidak berbeda jauh untuk setiap interval usia. Artinya baik pada usia kurang dari 20 tahun, 21-30 tahun, 31-40 tahun, 41-50 tahun dan usia lebih dari 50 tahun memiliki rerata skor kepuasan yang tidak terlalu jauh perbedaannya. Sehingga menghasilkan nilai p-value untuk uji oneway anova sebesar 0,190 . Karena nilai $p$ value $0,190>\alpha 0,05$ maka dapat disimpulkan bahwa tidak terdapat perbedaan kepuasan pada berbagai rentang usia. Berdasarkan tabel 9 dapat dijelaskan bahwa skor kepuasan berdasarkan jenis kelamin tidak berbeda jauh antara laki-laki dengan perempuan. Artinya baik pada laki-laki maupun perempuan memiliki rerata skor kepuasan yang tidak terlalu jauh perbedaannya. Sehingga menghasilkan nilai $p$-value untuk uji $t$-test sebesar 0,182 . Karena nilai $p$ value 0,182 $>\alpha 0,05$ maka dapat disimpulkan bahwa tidak terdapat perbedaan signifikan kepuasan pada laki-laki maupun perempuan. Hasil penelitian ini sejalan dengan penelitian yang dilakukan di RSGM FKG UNMAS bahwa dari 30 orang.

Hasil penelitian menunjukkan bahwa kualitas pelayanan di bagian Radiologi RSGM FKG UNMAS Denpasar yang terdiri dari dimensi reliability, responsiveness, assurance, emphaty, yang melakukan pemeriksaan rontgen di RSGM Terpadu FKG UNMAS Denpasar mayoritas responden menyatakan puas. Penyebab ketidakpuasan berdasarkan tinjauan hasil kuesioner bahwa pasien tidak puas terhadap kurangnya ketepatan waktu dalam pemberian pelayanan. Penyebab lainnya adalah penataan ruangan yang masih kurang. ${ }^{4}$

Pada penelitian yang telah dilakukan di Rumah Sakit Gigi dan Mulut Maranatha, pada gambar 4.1, dilihat dari tiap-tiap dimensi kualitas pelayanan, pada aspek Reliability (kehandalan) terdapat skor 95,25 \% dapat disimpulkan bahwa pada aspek reliability (kehandalan) memiliki hasil tingkat kepuasan yang tinggi yaitu melebihi skor 75\%, pada aspek Assurance (jaminan/keyakinan) didapatkan 
skor $94,6 \%$ yang memiliki tingkat kepuasan tinggi pada dimensi tersebut, aspek dimensi kualitas pelayanan Tangibles (penampilan) didapatkan skor $100 \%$ yang berarti memiliki tingkat kepuasan yang tinggi, dimensi kualitas pelayanan selanjutnya yaitu Empathy (perhatian) 100\% yang memiliki tingkat kepuasan yang tinggi pada dimensi tersebut. Pada dimensi kualitas pelayanan yang terakhir yaitu Responsiveness (ketanggapan) yaitu memiliki skor $100 \%$ yang artinya tingkat kepuasan pada dimensi kualitas pelayanan tersebut tinggi. Untuk gambaran kepuasan responden berdasarkan pengetahuan memiliki skor $98,5 \%$ dapat diartikan pengetahuan pasien tinggi mengenai pernyataan yang mencangkup pengetahuan. Penyebab ketidakpuasan pasien yaitu penjelasan petugas yang kurang jelas mengenai prosedur pemeriksaan dan bahaya-bahaya radiasi, lamanya waktu giliran untuk dilakukan pemeriksaan radiografi panoramik terlalu lama dan faktor lainnya yaitu biaya pemeriksaan radiografi dan proses pengambilan foto radiorafi yang berulang.

Tingkat kepuasan pasien merupakan cermin dari kualitas pelayanan di rumah sakit. Tingkat kepuasan pasien adalah perbandingan antara harapan dan kenyataan. Dikatakan puas jika harapan lebih dari kenyataan dan dikatakan tidak puas jika harapan kurang dari kenyataan. ${ }^{11}$ Ketidakpuasan pasien yang paling sering dikemukakan dalam kaitannya dengan sikap dan perilaku petugas, antara lain dalam hal ini yaitu aspek pelayanan yang diberikan pada pasien. Adapun variabel non medik yang menentukan kepuasan pasien yaitu tingkat pendidikan, latar belakang sosial ekonomi, budaya, lingkungan fisik, pekerjaan, kepribadian dan pengalaman hidup pasien. Kepuasan pasien dipengaruhi oleh karakteristik pasien seperti umur, pendidikan serta status sosial ekonomi. ${ }^{12}$

\section{SIMPULAN}

Pelayanan pemeriksaan radiografi panoramik yang baik pada periode 18 Juli - 18 Agustus 2017 memiliki tingkat kepuasan pada dimensi kualitas pelayanan reliability (keandalan) 95,25\%, Assurance (jaminan/keyakinan) 94,6\%, Tangibles (penampilan), Empathy (perhatian) dan Responsiveness (ketanggapan) 100\% pada analisis berdasarkan tingkat kepuasan, mayoritas responden berada pada interval 75\%-100\% dalam kategori tinggi.

\section{DAFTAR PUSTAKA}

1. Kepmenkes RI Nomor 1173/MENKES/ PER/X/2004 Tentang Rumah Sakit dan Mulut

2. Purnomosari, Etika. Deskripsi Dokter Gigi Terhadap Kualitas Foto Rontgen Periapikal di RSGM FKG Unpad. Fakultas Kedokteran Gigi Universitas Padjajaran. 2006.

3. Widyatelasari, Fitria. Gambaran Pelayanan Pemeriksaan Radiografi Gigi di Rumah Sakit Gigi dan Mulut FKG Unpad Berdasarkan Tingkat Kepuasan Pasien. Fakultas Kedokteran Gigi Universitas Padjajaran. 2006.

4. Fryanantha, Made. Pengaruh Kualitas Pelayanan Radiologi Terhadap Tingkat Kepuasan Menurut Persepsi Pasien. Fakultas Kedokteran Gigi Universitas Mahasaraswati. 2014.

5. Notoatmodjo, S. Ilmu Kesehatan Masyarakat. Jakarta : Rineka Cipta. 2012.

6. Anjani, Wike. Kepuasan Pasien Rawat Inap Terhadap Pelayanan Perawat di RSUD Tugurejo Semarang. Univarsitas Diponegoro. 2009.

7. Gaghana Veicy F, Siagian Iyone E.T, Palandeng Henry M. F, Monintja Tyrsa. Tingkat Kepuasan Pasien Unversal Coverage Terhadap Pelayanan Kesehatan di Puskesmas Tuminting Manad. Jurnal Kesehatan Masyarakat. 2014.

8. Setiawan I.. Tingkat Kepuasan Pasien Terhadap Pelayanan Perawat Di Unit Gawat Darurat Rumah Sakit Haji Jakarta. Jurnal Kesehatan. Fakultas Ilmu Keperawatan Universitas Indonesia. 2013.

9. Suryawati C, Dharminto, Shaluhiyah Z Penyusunan Indikator Kepuasan Pasien rawat Inap Rumah Sakit Di Provinsi Jawa Tengah. Fakultas Kesehatan Masyarakat dan Program Magister Ilmu Kesehatan Masyarakat Universitas Diponegoro. 2006.

10. Donabedian, A. 1980. The criteria and standars of quality. Michigan. Health Administration Press. 2014:1(1).99 - 108

11. Depkes, Pemenkes RI, No. 780/MenKes/Per/ VIII/2008, Tentang Penyelenggaraan Pelayanan Radiologi. Jakarta : Depkes RI. 2008.

12. Suryawati C, Dharminto, Shaluhiyah Z. Penyusunan Indikator Kepuasan Pasien rawat Inap Rumah Sakit Di Provinsi Jawa Tengah. Fakultas Kesehatan Masyarakat dan Program Magister Ilmu Kesehatan Masyarakat Universitas Diponegoro. 2006.

13. Anjani, Wike. Kepuasan Pasien Rawat Inap 
Terhadap Pelayanan Perawat di RSUD Tugurejo Semarang. Univarsitas Diponegoro. 2009.

14. Menkes RI. Peraturan Mentri Kesehatan RI NO.1173/Menkes/PER/X /2004 tentang Rumah
Sakit dan Mulut. Jakarta. 2004.

15. Jacobalis. Menjaga Mutu Pelayanan Rumah Sakit. Perhimpunan Rumah Sakit Seluruh Indonesia (PERSI). 2008. 